\title{
Challenging airway management
}

\section{Opening remarks}

\author{
Satoru Hashimoto $\cdot$ Shinhiro Takeda
}

Received: 30 October 2012/Published online: 5 December 2012

(C) Japanese Society of Anesthesiologists 2012

The 7th Symposium sponsored by the Journal of Anesthesia was held on June 9, 2012, during the 59th meetings of the Japanese Society of Anesthesiologists (JSA). To guarantee the success of this symposium, we, the chairpersons, chose "Airway Management", one of the most captivating topics for anaesthesiologists. This was the first time the prestigious Journal of Anesthesia Symposium covered a strictly clinical theme instead of basic research. As a result, despite being held early on a Saturday morning, these sessions stimulated much "standing-room only" participation, emphasizing the interest of JSA members in an updated review of this topic. The three accomplished speakers at this symposium were each invited to submit a manuscript of their respective presentations for this issue of the Journal of Anesthesia. These reviews will undoubtedly help readers understand the substance of the soon to be introduced JSA Airway Management Algorithm.

Dr. Shiro Isono, the first speaker, and Dr. Sato and colleagues, discussed the safety of perioperative airway management in obstructive sleep apnea (OSA). Approximately $0.4 \%$ of patients who undergo general anaesthesia have complicated airways and most of these patients have characteristics that are common in patients suffering from OSA. It is particularly noteworthy that $30 \%$ of Japanese patients who present with OSA are not obese. This review emphasized, on the basis of the authors' vast experience with OSA, the importance of mask ventilation [1].

\footnotetext{
S. Hashimoto $(\square)$

Department of Anesthesiology and Intensive Care Medicine, Kyoto Prefectural University of Medicine, Kyoto, Japan e-mail: satoru@koto.kpu-m.ac.jp

S. Takeda

Department of Anesthesiology and Intensive Care Medicine, Nippon Medical School, Tokyo, Japan

e-mail: shinhiro@nms.ac.jp
}

Dr. Takashi Asai, the second speaker, introduced the discussion of current strategies for difficult airway management, including the results of the 4th National Audit Project of the Royal College of Anaesthetists. He also pointed out that current airway management strategies remain imperfect and that a limited proportion of patients continue to experience major complications [2].

Finally, Dr. Koichiro Saito, an otorhinolaryngologist with abundant experience in percutaneous dilatational tracheostomy (PDT), reviewed the procedure with a historical perspective, and showed the importance of a collaborative approach in its performance. Although PDT should not be used in emergency, anaesthesiologists or intensivists who are not thoroughly surgically trained must master this technique, which will promote a deeper understanding of the airways [3].

As organizers of this symposium, we wish to reiterate that a recommended method for eradicating airway complications is still lacking. However, thorough understanding of their anatomical and physiological characteristics, with completion of advanced training, including such surgical procedures as PDT, would certainly reduce the incidence of adverse events. Finally, readers must remember that overconfidence is man's greatest enemy and that, sometimes, unforeseen events occur when you least expect them.

\section{References}

1. Sato Y, Ikeda A, Ishikawa T, Isono S. How can we improve mask ventilation in patients with obstructive sleep apnea during anesthesia induction? J Anesth. 2012. doi:10.1007/s00540-012-1520-5.

2. Asai T. Strategies for difficult airway management-the current state is not ideal. J Anesth. 2012. doi:10.1007/s00540-012-1521-4.

3. Saito K, Morisaki H. Percutaneous dilatational tracheostomy: collaborative team approach for safe airway management. J Anesth. 2012. doi:10.1007/s00540-012-1522-3. 